RERLATIE MIE MALLED

Campinas-SP, v.38 n.2, pp. 827-852, jul./dez. 2018

\title{
Die Autonomie des Übersetzers - DESCONSTRUINDO OS PRESSUPOSTOS METAFÍSICOS DE ESTUDOS TRADICIONAIS DA TRADUÇÃO
}

\author{
Rafael Guimarães Tavares da Silva'
}

Resumo: Tomando como pilares de nossa argumentação alguns pontos fundamentais da teoria linguística de base pós-estruturalista (a partir de Jacques Derrida, Geoffrey Bennington e suas tradutoras para o português), o presente artigo busca questionar algumas "verdades" tradicionalmente aceitas na teoria e na prática da tradução (mesmo entre autores radicais, como Walter Benjamin e Henri Meschonnic, por exemplo). Criticando certas noções de "originalidade", "literalidade", "fidelidade" e outras afins àquilo que Derrida chamaria de uma "metafísica da presença", empreendemos demonstrar de forma convincente a autonomia que é prerrogativa de todo tradutor, mesmo quando explicitamente a recusa. Não se trata, portanto, de uma tentativa de reivindicar maior autonomia para o ato de traduzir, mas de constatar uma situação de fato: todo tradutor é autor do texto que concebe. Nesse sentido, todo texto - quer ele seja "original", quer ele seja uma tradução - é dotado de uma originalidade que o autoriza a ser traduzido subsequentemente (e de modo indefinido). Essa conclusão contraria um dos axiomas fundamentais do texto "Die Aufgabe des Übersetzers" (tradicionalmente traduzido como "A tarefa do tradutor" e que serve de prefácio às traduções de Benjamin aos "Tableaux parisiens" [Quadros parisienses] de Charles Baudelaire), qual seja, o de que uma tradução não pode ser novamente traduzida. Nossa argumentação culmina justamente na tradução do poema "Der Schwan", de Benjamin, proposto como tradução do poema "Le cygne", de Baudelaire: sugerindo que todo tradutor é autor do texto da tradução e entra, por isso, num jogo de assinaturas e contra-assinaturas, acreditamos demonstrar a originalidade do poema de Benjamin ao vertê-lo por sua vez ao português, abrindo assim todo um novo campo de investigações para a teoria e prática da tradução.

Palavras-chave: Walter Benjamin; Jacques Derrida; Teoria da Tradução.

1 Doutorando do POS-LIT, FALE, UFMG (Programa de Pós-Graduação em Letras: Estudos Literários, Faculdade de Letras da UFMG): <gts.rafa@hotmail.com>. 
A traduçãoéum processo de leitura e escritura, de recepção e produção textuais: produzir a partir da recepção de um texto, dito "original”, um novo texto. Eis, portanto, a matéria-prima do tradutor: textos - que, por meio da leitura e da escritura, ele conhece e dá a conhecer. Entre o princípio e o termo desse processo - dessa construção -, outros textos são solicitados, e o inesperado acontece em tais intervalos. Mas não se restringe a eles: o inesperado vem ainda antes de seu princípio e depois de seu termo. Mesmo quando calculado - ou antes, nessa medida mesmo. Sejamos claros: a tradução é o registro da leitura de um texto (ou seja, dispor os significantes textuais numa nova rede de relações com outros significantes) por meio da escritura de um novo texto (ou seja, a passagem desta "nova rede de relações com outros significantes" a um novo conjunto de significantes textuais). ${ }^{2}$

Poderíamos entender a palavra "texto" em sentido lato ${ }^{3}$ - ou seja, como um arranjo complexo dos mais diversos tipos de significantes. Nesse sentido, um poema, um quadro ou uma sinfonia seriam tão textos quanto este ensaio acadêmico. Todos como produtos - tendo existência material em seus significantes - capazes de serem pontos de partida (ainda que sempre diferidos) de uma infinita cadeia de novas relações com outros significantes. Uma cadeia infinita, sim, pois o processo de leitura - de disposição dos significantes do texto "original" numa nova rede de relações com outros significantes - é, em larga medida, um processo subjetivo de tentativa de construção de sentido (portanto, sempre por se fazer).

Vamos nos ater, contudo, ao que convencionalmente se entende pela palavra "texto", ou seja, como um arranjo complexo de significantes escritos. ${ }^{4}$ Do que dissemos acima, segue-se que a tradução envolve diretamente um processo de leitura, vindo inclusive a se confundir

2 Cf. Bennington (1991, p. 50). Ou ainda, nas palavras de sua tradutora, Anamaria Skinner (1996, p. 43), “[...] se 'escritura' sempre quis dizer significante, que remete a um outro significante, e se, já vimos isso, todo significante só remete aos outros significantes, então 'escritura' nomeará propriamente o funcionamento da língua em geral.”

3 Conforme o que diz Derrida (1990, p. 422) do “[...] texte en général - qui ne se limite pas à ce que l'on appelle des écrits dans des bibliothèques ou à des programmes d'ordinateurs [...]". Ou seja, no sentido daquilo que ele afirma sobre o texto em geral, não limitado aos escritos nas bibliotecas ou aos programas de computador.

4 Poderíamos relacionar o que chamamos "texto" (no sentido estrito) ao sprachliche Gebilde de Benjamin (1923, p. VIII). Para maiores detalhes sobre tal expressão, cf. Lages (2013, p. 103, n. 41). 
com a mesma. ${ }^{5}$ A partir desse entrelaçamento, elaborou-se um célebre paralogismo pelo qual os estudos de tradução são responsáveis: o de que a leitura feita pelo tradutor seja privilegiada com relação à de qualquer outro leitor do texto "original”. Lages (2007, p. 69), em seu estudo sobre a obra de Benjamin, por exemplo, afirma que:

Evidentemente, o tradutor não pode ser equiparado aos leitores em geral; no âmbito de seu ambiente cultural, ele é antes de mais nada o leitor por excelência, e leitor privilegiado do texto que irá traduzir. Entretanto, essa situação, de fato excepcional, não pode, do ponto de vista defendido no presente trabalho, levar a que se exija de um tradutor ser capaz de identificar, em absoluto, todo o inescrutável - e muitas vezes, inconsciente - espectro das intenções comunicativas de um autor.

Ora, tendo em vista a definição de "texto" anteriormente explicitada, fica evidente que dela excluímos (mais até do que a exigência da capacidade de identificação entre o tradutor e quem quer que tenha composto o texto a ser traduzido), a mera consideração da existência de um "inescrutável - e muitas vezes, inconsciente - espectro das intenções comunicativas de um autor". O texto é composto por significantes (que na leitura serão dispostos numa nova rede de relações com outros significantes), não por signos. ${ }^{6}$ Entendemos, portanto, que no sistema de diferenças que é a língua, todo significante funciona remetendo a outros significantes, sem que jamais se alcance o significado final ou primordial (estável e estabilizante). ${ }^{7} \mathrm{O}$ significado de um texto "em si mesmo" é uma utopia. ${ }^{8}$

5 Cf. Bennington (1991, p. 157). Segundo Skinner (1996, p. 120): "Pode-se dizer o mesmo quanto à leitura em geral, de que a tradução aqui é somente um caso particular”.

6 Em sentido análogo, Haroldo de Campos (2013a, p. 1), em seu artigo "Da tradução como criação e como crítica”, cita a tese de Albrecht Fabri, segundo a qual: "[...] as obras artísticas 'não significam, mas são"'.

7 Cf. Bennington (1991, pp. 35-36). Segundo Skinner (1996, p. 34), em sua tradução das palavras daquele: "No sistema de diferenças que é a língua, todo significante funciona remetendo a outros significantes, sem que se chegue nunca a um significado. Procurem no dicionário o significado de um significante desconhecido, vocês encontrarão outros significantes, nunca significados. Já foi dito, um significado não é mais do que um significante posto numa certa posição por outros significantes: não existe significado ou sentido, só há 'efeitos' [...]".

8 Também Meschonnic (1999, p. 111) parece concordar com essa ideia. Nas palavras da tradução de Ferreira e Fenerich (2009, p. 32): "Esquecemos que ninguém tem acesso direto à linguagem: mas sempre através das ideias que se tem dela, e que são situadas. Pois o texto só funciona através da leitura, e esta comporta um elemento que lhe é invisível, mas que não é transparente, que é de ordem histórica: a ideia que se tem do funcionamento da linguagem, e do texto". 
Sequer o autor seria capaz de instaurar um significado primeiro (aquele que, necessariamente por meio de uma nova leitura, ele acreditaria ter tido em mente quando plasmou os significantes) ou um significado último (aquele que, necessariamente por meio de outra leitura - ainda que uma "última" leitura - ele acreditaria ser plasmado em sua mente pelos significantes) .9

Toda leitura é um processo, em larga medida, ${ }^{10}$ subjetivo de tentativa de construção de sentido. Não se trata estritamente de um processo de construção de sentido, mas da sua tentativa, pois "a leitura não tem fim, ela está sempre por-vir como trabalho do outro (e nunca do Outro) - um texto não encontra nunca seu repouso na unidade e no sentido enfim (re)descoberto" (SKINNER, 1996, p. 47). ${ }^{11}$ Nesse processo subjetivo é que fatores exteriores ao texto - ao seu arranjo complexo de significantes escritos - necessariamente agem sobre a tentativa de construção de significado pelo leitor. Referimo-nos aos contextos de escritura (criação) e/ou de leitura (recepção) do texto. ${ }^{12}$

É bem conhecido o início de Die Aufgabe des Übersetzers (comumente traduzido por "A tarefa do tradutor"), da autoria de Walter Benjamin, no qual ele nega veementemente que se leve em consideração o receptor de uma obra de arte ou de uma forma artística a fim de conhecê-la melhor. Acompanhemos aqui as palavras de Lages (2013, pp. 107-108), com as quais ela traduz outro trecho desse mesmo texto:

Existe uma maturação póstuma mesmo das palavras que já se fixaram: o que à época do autor pode ter obedecido a uma tendência de sua linguagem poética, poderá mais tarde esgotar-se; tendências implícitas podem surgir como novas da forma criada. Aquilo que antes era novo, mais tarde poderá soar gasto; o que antes era de uso corrente pode vir a soar arcaico. Procurar o

9 Cf. Bennington (1991, p. 153). Nas palavras de Skinner (1996, p. 117): "Deve-se então repensar a leitura como uma relação de assinatura e de contra-assinatura, o que permite pensar no que um texto permanece essencialmente aberto ao outro (à leitura). A assinatura do texto reclama a contra-assinatura do leitor [...]". O que leva ao apontamento de que: "Eis aí por que um texto nunca está fechado em si mesmo, apesar do esforço do signatário que quer se apropriar dele”.

10 É preciso atentar a este "em larga medida”, expressão limitadora da alegada subjetividade, uma vez que, se por um lado, nenhum texto prescreve uma leitura inevitável (sequer o texto da lei), por outro, nenhum texto admite um "qualquer coisa” puro, o que também não seria uma leitura. Cf. Bennington (1991, p. 157); Skinner (1996, p. 120).

11 Cf. Bennington (1991, p. 56).

12 Cf. Meschonnic (1999, pp. 21-22). Ou, nas palavras de Ferreira e Fenerich (2010, p. XXVII): "Há o quem, o que, o como, há também o quando do traduzir: as distâncias de data e sua variação, entre o tempo do original e o da tradução". 
essencial de tais mudanças (bem como das igualmente constantes mudanças de sentido) na subjetividade dos pósteros, em vez de buscá-lo na vida mais íntima da linguagem e de suas obras, seria, mesmo se admitirmos o mais tosco psicologismo, confundir causa e essência de um objeto; expresso de modo mais rigoroso: seria negar um dos processos históricos mais poderosos e produtivos por impotência do pensamento. E mesmo se se pretendesse transformar o ponto final do autor no tiro de misericórdia da obra - isso não salvaria aquela defunta teoria da tradução. ${ }^{13}$

Parece-nos digno de nota que se fale de uma busca na "vida íntima da linguagem e de suas obras" sem se notar que isso envolve um fator tão subjetivo na escolha do que será considerado o essencial de tais mudanças quanto o que há quando se leva em conta "a subjetividade dos pósteros" (e mesmo a dos contemporâneos da obra ou de seu próprio autor). O juízo de valor negativo com relação a essa tomada de posição qual seja, a de quem leva em consideração certos aspectos contextuais na leitura de um texto - é sinal evidente de um posicionamento ideológico - tão (in)válido quanto qualquer outro - do qual tal trecho parece querer mostrar-se inconsciente. Mas aquilo que se chama "maturação póstuma" das palavras evidencia a consciência de que os significantes de um texto, embora possam permanecer materialmente os mesmos com o passar do tempo (ainda que, não raro, até eles difiram), são dispostos numa rede perpetuamente modificada de relações com outros significantes. ${ }^{14}$ Qualquer tentativa de apreender o "essencial de tais mudanças" na "vida mais íntima da linguagem e de suas obras" é nada mais do que apelar para argumentos de uma ordem te(le)ológica.

Toda leitura é um processo subjetivo de tentativa de construção de sentido que se dá num ponto do espaço-tempo, cujas coordenadas (o que se chama contexto) garantem a singularidade. Por isso mesmo, cada leitura é um evento singular que não pode ser de todo repetido. ${ }^{15}$ Além disso, uma vez que se trata de um processo subjetivo, a escolha (consciente ou não) de se levarem em conta determinados contextos (como os de produção ou de recepção, por exemplo) na tentativa de construção de sentido do texto faz necessariamente parte do processo de leitura. Toda escolha desse tipo reflete determinados interesses e jamais é neutra (mesmo quando

${ }_{13}$ Cf. Benjamin (1921, p. X).

14 É o que também Borges (1971b), em seu texto “Pierre Menard, autor del Quijote”, torna mais do que evidente.

15 Parafraseamos aqui as palavras de Bennington (1991, p. 85). Cf. ainda: Skinner (1996, p. 69). 
inconsciente). Nenhum texto é suficientemente "ele mesmo" para abrir mão de alguns de seus contextos, ao mesmo tempo em que nenhum contexto pode verdadeiramente se encerrar ou encerrar o sentido de um texto. $^{16}$

\section{II}

Se todo texto, por um lado, é capaz de suscitar àqueles que o leem um contínuo processo de tentativa de construção de sentido, por outro, é o produto de um processo inverso. Ou seja, todo texto é o resultado da passagem de uma rede de relações entre os mais diversos tipos de significantes (conforme essa rede seja estabelecida por aquele que intenta escrever) para o conjunto de significantes que passam a compor o texto. ${ }^{17}$ Vale lembrar que, embora o escritor possa acreditar ter tido em mente um ou mais significados ao longo do processo de escritura, uma vez que o conjunto de significantes seja dado à luz, a inexistência daqueles significados torna-se manifesta. Isso porque significado algum sobreviveria (se ele acaso tivesse de fato existido) à inscrição dos significantes. Eis aí a fonte da melancolia de todo escritor que se relê. Essa releitura é o momento da confrontação entre o pai e aquele filho que já não pode de todo compreender (e que, na verdade, nunca pôde).

Ainda assim, o processo de escritura é, em certa medida, um processo deleitura-leitura dos significantes potencialmente infinitos quecompõem o mundo e suscitam (àqueles que os "leem") um contínuo processo de tentativa de construção de sentido. ${ }^{18}$ Por isso, a escritura é, ainda em mais larga medida do que a leitura, um processo subjetivo. Os significantes legíveis - capazes de suscitar um contínuo processo de tentativa de construção de sentido - são, por sua vez, potencialmente infinitos. ${ }^{19}$ Eis

16 Cf. Bennington (1991, p. 88); Skinner (1996, p. 70).

17 Essa compreensão derridiana do processo de significância (da qual tratamos no início do presente artigo) parece perpassar o pensamento de Meschonnic, embora a certa altura de seu texto esse autor critique alguns aspectos da obra do filósofo franco argelino (MESCHONNIC, 1999, pp. 96-98). Cf. ainda: Ferreira; Fenerich (2010, pp. 19-21). Para nos atermos a um único exemplo do rastro derridiano (ainda que recalcado) nessas obras, cf. Meschonnic (1999, p. 146); Ferreira; Fenerich (2010, p. 62).

18 Cf. Bennington (1991, p. 96). Nas palavras de Skinner (1996, p. 76): “Ora, eis aí que Derrida, embalado pela importância da linguagem, nega exatamente esta situação [a de que a linguagem tenha um fora] fazendo deste mundo (que em si deve ser mudo) uma parte da linguagem, do texto [...]".

19 Em seu texto "La biblioteca de Babel", Borges (1971a) faz interessantes considerações sobre a vertigem desse infinito potencialmente contido no exercício da escritura. 
aí a vertigem de todo aquele que se propõe a escrever. Tal escritura é o momento da eleição dos significantes - potencialmente infinitos e capazes de suscitar continuamente novas tentativas de construção de sentido e de sua fixação na quantidade finita de significantes do texto, capazes de suscitar no leitor continuamente novas tentativas de construção de sentido.

De tudo quanto expusemos, talvez esteja claro a que ponto leitura e escritura confundem-se num movimento que já não se deixa compreender por meio de uma divisão em etapas ou momentos determinados. Ler é, em certo sentido, escrever uma determinada leitura. Escrever, por outro lado, é também ler uma determinada escritura. O critério tradicionalmente empregado para se diferenciarem essas etapas ou momentos (embora eles sempre tenham estado amalgamados), baseia-se na atitude adotada pelo sujeito (leitor ou escritor) com relação ao objeto (texto): segundo essa visão tradicional, se a passividade, por um lado, seria característica do ato de leitura (como mera recepção passiva de um texto e seus significados), por outro, a atividade seria característica do ato de escritura (como produção ativa de um texto e seus significados). Poderíamos citar alguns exemplos simples que tornariam evidente a falácia de tais concepções: em certas peças jurídicas ou exercícios de retórica, um argumento pode ser escrito segundo algumas convenções e lugares-comuns quase à revelia de seu autor (segundo a fórmula contemporânea do "Ctrl C + Ctrl V", isto é, do "copiar e colar"); no outro extremo, certas obras literárias dos séculos XIX e XX (tais como o livro-poema "Un coup de dés jamais n'abolira l'hasard", de Mallarmé, ou o work in progress de James Joyce, Finnegans Wake), mais até do que meramente permitir a participação ativa do leitor, exigem-na. Isso para ficarmos apenas nos casos mais evidentes de uma dubiedade que solapa desde sempre tal dicotomia e que esperamos estar por ora suficientemente clara. Nas palavras de Skinner (1996, p. 46):

Aqui, as divisões usuais entre autor e leitor, emissão e recepção, envio e chegada não são estanques. Na qualidade de autor, eu já sou destinatário no momento em que escrevo. [...] O ato de escrever está de início dividido por essa cumplicidade entre escritura e leitura, o que impede logo que se possa tão facilmente considerar esse ato como um ato, confundindo com isso mesmo a oposição atividade/passividade (ou produção/consumo) que organiza e subentende a compreensão corrente da escritura. ${ }^{20}$

20 Cf. também: Bennington (1991, p. 54). 


\section{III}

Tendo chegado a esse ponto da nossa própria construção, gostaríamos de retomar o início deste artigo. Reiteramos hic et nunc que a tradução é um processo de leitura e escritura de textos. Daí reafirmarmos a matéria-prima do tradutor: textos. O processo operado por ele consiste em lê-los e escrevê-los, além de, ao mesmo tempo, escrevê-los e lê-los. Entre o princípio e o termo desse processo, contudo, ocorrem inúmeras (des) construções. Parte-se de um texto e chega-se a um novo texto. Entre o texto de partida e o texto de chegada, bem como antes e depois dos mesmos, advêm imprevisíveis (des)construções.

Esperamos ter anteriormente tornado explícito em que medida se dá a imprevisibilidade de tais (trans)tornos. Em toda leitura/escritura, cabe a cada escritor/leitor uma imensa liberdade para se valer dos mais diversos métodos a fim de realizar essa empreitada. Muitos se orientam por um dos dois polos da velha dicotomia entre forma e conteúdo (significante e significado; corpo e espírito) ou por ambos a um só tempo, ${ }^{21}$ enquanto outros não deixam de se nortear pelos contextos de produção da obra ou de sua recepção (seja no presente, seja no passado). Os mais destemidos, contudo, colocam mãos à obra ignorando - ou fingindo ignorar - os métodos tradicionalmente empregados e seguem batendo seus pilares a seu bel prazer. Apesar de tais diferenças, ou antes, na medida mesmo de sua (co)existência, podemos constatar a impossibilidade de que uma dessas formas seja tida como a única "correta", ou como a única exclusivamente adequada para se tentar a execução de tal obra ${ }^{22}$ - por isso ela sempre será imprevisível. Muitos sucumbem no processo e não chegam a completar o projeto que esboçaram. Outros constroem edifícios bastante diversos daqueles que pretenderam no começo. Uns (muito poucos) executam com razoável precisão o planejamento que tinham em mente quando bateram as fundações de seu edifício. Todos, contudo, diferem não só durante tais operações, mas antes e depois delas - nas (des)construções que levam a elas e que delas se elevam. Em cada um dos seus (trans)tornos. Assim o é: o

$21 \mathrm{O}$ que parece ter sido a opção dos poetas-tradutores concretistas. Suas considerações teóricas têm implicações para a tradução de modo geral, embora sejam voltadas sobretudo para a poética, já que: "A informação estética é a que menos suporta a separação do código particular em que foi materializada: sua fragilidade sob esse ângulo é máxima. Tradução de poesia é, pois, substituição do código especialíssimo e fragílimo por outro de análoga natureza e propriedades. Trata-se de um complexo decifrar para um novo e complexo cifrar" (CAMPOS, 2013d, p. 24).

22 Cf. Derrida (1987, p. 203). Parafraseando sua tradutora, Barreto (2002, p. 12), podemos afirmar justamente que a multiplicidade de idiomas vem sempre limitar uma tradução "verdadeira", uma entr'expressão transparente e adequada. 
inesperado se tece não apenas entre a leitura/escritura do texto de partida e a escritura/leitura do texto de chegada, mas antes e depois das mesmas. E nesses intervalos (se é que poderíamos chamá-los ainda intervalos), a tradução acontece. Não como um processo de mera transposição - de signos, significados ou significantes -, mas enquanto ato de verdadeira criação. ${ }^{23}$ Afinal, toda tradução é um novo texto. ${ }^{24}$

Levando em conta tudo o que reiteramos, evidencia-se que a tradução envolve diretamente um processo de escritura. A escritura na tradução, contudo, foi tradicionalmente entendida a partir de uma profunda dependência da obra "original", levando muitos teóricos e tradutores a elaborar outro célebre paralogismo nesse campo de estudos: o de que a tradução ideal seria "transparente". A bibliografia especializada, partindo da concepção de que o texto "original" seria sempre superior à tradução sendo esta última considerada uma espécie de excrescência inadequada -, defendeu com frequência o apagamento do tradutor no texto que escreve. Se essa naïveté pode parecer-nos inacreditável (ou dissimuladamente astuta), vale lembrar que o próprio Benjamin não escapou a tal ilusão. ${ }^{25}$ Desde meados do século XX, contudo, tradutores e teóricos da tradução propuseram uma série de questões e reflexões a fim de promover uma revisão desse engano. ${ }^{26}$ A própria Lages (2007, pp. 69-70), em seu estudo sobre Benjamin, faz uma crítica a tal entendimento nos seguintes termos:

23 Arriscamosa imagem da construção (como metáfora da tradução) porseu valor de processo, evitando a ideia de transporte de mercadorias-informações. A crítica de Meschonnic (1999, p. 19) é exata no que tange a um traduzir baseado na transposição sígnica. Ferreira e Fenerich (2010, p. XXV) reiteram-no pungentemente: “Barqueiro é uma metáfora agradável. O que importa não é fazer passar. Mas em que estado chega o que se transportou para o outro lado. Na outra língua. Caronte também é um barqueiro. Mas ele faz atravessar os mortos. Aqueles que perderam a memória. É isto o que acontece a muitos tradutores".

24 Benjamin (1923, p. X), em seu texto sobre a tarefa do tradutor, parece apontar um entendimento nesse sentido. Seu apego à noção de "Original", contudo, impede que ele tire as conclusões mais radicais de suas intuições. Cf. Lages (2013, p. 107).

${ }_{25}$ Cf. Benjamin (1927), p. XV. Nas palavras de Lages (2013, p. 115), em sua tradução a "Die Aufgabe des Übersetzers": "A verdadeira tradução é transparente, não encobre o original, não o tira da luz; ela faz com que a pura língua, como que fortalecida por seu próprio meio, recaia ainda mais inteiramente sobre o original."

26 As palavras de Borges (1996, p. 239), em "Las versiones homericas", são emblemáticas desse movimento que enxerga o conceito de texto definitivo como algo da religião ou do cansaço, na medida em que pressupor que toda recombinação de elementos seja obrigatoriamente inferior a seu original é pressupor que o esboço 9 é obrigatoriamente inferior ao esboço $\mathrm{H}$, já que não pode haver senão esboços. Nas palavras dele: "Presuponer que toda recombinación de elementos es obligatoriamente inferior a su original, es presuponer que el borrador 9 es obligatoriamente inferior al borrador $\mathrm{H}$ - ya que no puede haber sino borradores. El concepto de texto definitivo no corresponde sino a la religión o al cansancio" . Cf. ainda: Meschonnic (1999, p. 23); Ferreira; Fenerich (2010, p. XVIII). 
De acordo com uma concepção corrente na prática, e também nas reflexões teóricas e críticas sobre tradução, o tradutor não deveria "aparecer", deixar marcas suas no texto traduzido, devendo procurar neutralizar ao máximo sua operação sobre o texto original, o qual é definido a priori como superior. Essa atitude deriva de uma visão que considera o texto original como um produto acabado, fechado, imutável, completamente imune às vicissitudes histórico-temporais a que está exposto todo produto da cultura humana.

Ora, já vimos que nenhum texto - e, vale ressaltar, nem mesmo o mais canônico dos textos - pode se tornar "um produto acabado, fechado, imutável”. Se essas obras fossem assim, não haveria tantos estudos recentes, muitos deles promovendo releituras geniais e originalíssimas, de textos canônicos tão arcaicos (nas várias acepções etimológicas do termo) quanto a Ilíada e a Odisseia, ${ }^{27}$ para ficarmos apenas nos exemplos mais óbvios. Isso é outra evidência de que o "sentido final" de um texto jamais foi encontrado e jamais poderá sê-lo - posto que, como argumentamos anteriormente, o sentido próprio de um texto não existe. A crença nesse "sentido final", contudo, persiste, e isso se deve ao fato de que certos leitores/escritores se deixam levar por algo que seríamos tentados a chamar de arrogância, mas que, por consideração, reputaremos fruto da mesma naïveté anteriormente mencionada. ${ }^{28}$ Afinal, alguns tradutores e intérpretes insistem em fundar seu próprio discurso na autoridade de um autor defunto (isto é, todo autor após publicar sua obra), colocandose como os representantes autorizados daquele, num fenômeno de verdadeira "mediunidade hermenêutica". 29

27 No campo dos estudos clássicos, a revolução provocada pelos estudos de Parry (1971) e Lord (1971) é apenas o exemplo mais extremo desse fenômeno. Por outro lado, as releituras dos poemas homéricos por Weil (2014) ou Horkheimer e Adorno (2013) suscitam interessantes questões filosóficas.

28 Nesse sentido, é curioso que, justamente num estudo sobre Benjamin, Gagnebin (2009, p. 1, n.1, grifo nosso) afirme que citará as duas traduções brasileiras até então existentes do texto "Über den Begriff der Geschichte", "tomando a liberdade de melhorá-las, quando for necessário".

29 A expressão foi cunhada por Araújo (2009, pp. 245-246), tendo sido empregada no seguinte trecho: "Digamos, por ora, quanto a isso, que tal fenômeno de mediunidade hermenêutica, por assim dizer - e, talvez, essa seja uma expressão tautológica, já que a operação hermenêutica parece mesmo implicar, por definição, uma 'conversa com os mortos', portanto uma relação mediúnica com o autor que então se lê hermeneuticamente -, possa ser mais bem compreendida de maneira inversa, isto é, não como um fenômeno pelo qual o fantasma do autor morto venha a falar pela voz de um comentador contemporâneo abnegado - que se quereria, bem entendido, um não-sujeito do discurso -, mas pelo qual uma certa voz contemporânea se faça ouvir (à revelia?) justamente pela boca de um fantasma invocado pelo discurso interpretante". 
A sugestão (ou mesmo a exigência) de que um tradutor deva buscar a "transparência" em seu texto talvez não se mostre tão paradoxal à primeira vista, mas, se levarmos em conta tudo o que foi dito com relação ao movimento de leitura/escritura próprio a toda e qualquer tradução, ficará claro quão absurdo é tal entendimento. Ele pressupõe, ainda que dissimuladamente, a aceitação da ideia segundo a qual uma escritura poderia anular-se enquanto materialidade, a fim de realizar-se como significado puro. Ora, isso implicaria a existência de um escritor que não escreve. Sua linguagem imaterial (posto que não escrita), isenta de certas características dos processos linguísticos mundanos (a própria différance entre tais), só poderia ser entendida como uma espécie de "língua pura"3o (ou antes, "depurada"). Na medida em que todo tradutor escreve e que toda escritura só se faz possível na inscrição de seus significantes, evidencia-se que um tradutor jamais poderá ser "transparente" (bem como jamais pôde sê-lo), e que qualquer tradução arrogando a ideia de "transparência" é um produto de má-fé ou da ignorância-de-si. ${ }^{31}$

Reiteremos: traduzir é escrever e escrever é traduzir. ${ }^{32}$ Todo texto é uma espécie de tradução e toda tradução é um novo texto. Essa tese que, a partir da exposição de diversos aspectos do problema, deve parecer agora clara o bastante para que possamos sintetizá-la em palavras de sabor aforismático, foi tradicionalmente rechaçada pelos teóricos e práticos da tradução. No intuito de promover uma revisão desse posicionamento, assumimos o esforço de empreitada inscrito ao longo deste artigo. Ou seja, desejamos apresentar e defender a tese de que todo tradutor é autônomo. Não se trata aqui de mera retórica buscando operar uma modificação no status daquele que traduz (qual seja, "libertá-lo" da tirania imposta pela ideia de "original"), mas de se constatar uma situação de fato: toda tradução é um novo texto escrito por alguém autônomo. 33

30 Benjamin mostra-se partidário dessa concepção em seu ensaio sobre a tarefa do tradutor. O que chamamos aqui "língua pura" pode ser entendido como o que Derrida relaciona, sob o nome de "Expression", ao Ausdruck de Husserl. Cf. Derrida (1972, p. 45); Magalhães (1994, p. 50).

${ }_{31}$ Cf. Meschonnic (1999, p. 30); Ferreira; Fenerich (2010, p. XXXIII).

32 Nesse sentido, Haroldo de Campos, num artigo de 1983 (no qual avalia a poética da tradução de Valéry), destaca, como tópico particularmente relevante ao pensamento do poeta francês, "a ideia da literatura como uma operação tradutora permanente escrever é traduzir - logo a relativização da categoria da originalidade em favor de uma intertextualidade generalizada" (CAMPOS, 2013c, p. 62).

$33 \mathrm{O}$ projeto de uma poética da tradução, de Meschonnic, pareceria, à primeira vista, concordar com o que defendemos. Contudo, ele busca operar uma transformação - não constatar uma situação de fato. A título de exemplo, cf. Meschonnic (1999, p. 33). Nesse mesmo sentido, cf. ainda: Ferreira; Fenerich (2010, p. XXXVI). 
Essa tese, contudo, parecerá idiossincrática diante de um dos poucos aspectos preponderantemente unânimes para a tradição em tradução. Mesmo os teóricos mais recentes revelam-se inflexíveis nesse ponto. Lages (2007, p. 215), por exemplo, sustenta que:

\begin{abstract}
Uma tradução já não é mais o texto original, passado, e não chega ainda a ser um novo texto, completamente autônomo, pois ainda se vincula, de alguma forma, ao texto a partir do qual foi criada. Como o tempo, uma tradução é caracterizada por uma certa instabilidade, uma vez que se define como mediadora, não apenas entre duas culturas espacialmente distantes, mas também entre dois momentos históricos diversos. A tradução ocupa um espaço de passagem, no qual não se fixam momentos cristalizados, identidades absolutas, mas se aponta continuamente para a condição diferencial que a constitui.
\end{abstract}

O lugar de uma construção ainda por se fazer e que é ocupado por qualquer tradução, apesar disso, não é diferente daquele que ocupa toda escritura/leitura predecessora sua. ${ }^{34}$ Ao contrário do que afirma Lages (um tanto quanto vagamente), a tradução não se vincula, "de alguma forma, ao texto a partir do qual foi criada”. Se é verdade, por um lado, que ela parece ter um início (ainda que já diferido) no texto "original", ela chega a sua conclusão (também a diferir-se) - depois de uma imprevisível empreitada de (des)construções e (trans)tornos - fundamentalmente diversa. Sim, a condição da tradução é diferencial, e as consequências disso são a liberdade e a autonomia do tradutor. Ainda que na tradução se pareça abrir mão de alguns aspectos dessas premissas em prol daquilo que se julga o mais adequado ao novo texto (mesmo que sob as alegações tradicionais de fidelidade ao espírito da obra, à letra do texto etc.), o tradutor permanece desvinculado de toda ideia apriorística relacionada a uma dependência face aos possíveis significados ou significantes do texto “original”, bem como às intenções de seu autor ou às várias recepções de sua obra. Inclusive, o movimento de escolha dos aspectos da obra "original" que serão levados em conta no momento de escritura da tradução (ou seja, os aspectos "mais importantes" da obra na opinião daquele que a lê a fim de traduzi-la) faz parte de uma retórica auto justificante da tradução

34 Cf. Derrida (1987, p. 230). Numa passagem em que se trata de questões jurídicas ligadas ao direito do autor, Barreto (2002, p. 62) afirma o seguinte: “O retorno da palavra 'tarefa' é bastante notável, em todo caso, por todas as significações que ela tece em rede, e é sempre a mesma interpretação avaliadora: dever, dívida, taxa, contribuição, imposto, despesa de herança e sucessão, nobre obrigação, mas labor a meio caminho da criação, tarefa infinita, não acabamento essencial, como se o presumido criador do original não estivesse, ele também, endividado, taxado, obrigado por um outro texto, a priori tradutor". 
enquanto tal. Ou seja, o tradutor pode (e deve) definir esses aspectos "mais importantes", buscando justificá-los da forma mais persuasiva para seus leitores, mas ciente de que tal definição se dá sempre a posteriori e jamais é necessária ou objetiva.

Se toda tradução é um novo texto, o que diferencia um texto "original" de um texto traduzido? Por que distinguimos a tradução, se o status dos dois textos parece ser o mesmo, uma vez que ambos se realizam por meio de um múltiplo movimento de leitura/escritura? Ou antes, o que caracteriza a tradução enquanto tal?

Todas essas questões orbitam um complexo problema que pareceria de ordem ontológica. Não temos a pretensão de exaurir as inúmeras possibilidades de abordagem dessa matéria, mas desejamos destacar seus pontos cardeais para que novas indagações possam ser feitas e tratadas no futuro. Pensando o processo de tradução de modo geral, acreditamos que todo tradutor deva necessariamente remeter-se, num momento ou noutro de seu projeto, aos seguintes pontos: diálogo com a tradição; leitura de um texto específico; escritura de um novo texto; retórica da tradução. Cada um desses tópicos - que não são, de modo algum, diferentes fases da tradução, nem categorias estanques desse processo - mereceria ser tratado longamente, mas vamos nos concentrar naquilo que julgamos o essencial com relação a cada um deles.

Toda tradução concebe-se enquanto um diálogo explícito com a tradição. Nesse diálogo, o tradutor desfruta de um direito à liberdade quase irrestrito ${ }^{35}$ diante de muitos dos autores que lhe precederam. Em vista de seu contexto - ou apesar dele -, o tradutor tem a liberdade de escolher, dentre a miríade de obras disponíveis nas línguas em que for fluente, o texto que melhor convém a seus objetivos. Sejam tais objetivos acadêmicos, literários, técnicos, religiosos (dentre muitos outros possíveis), a escolha do tradutor é um momento crítico, pois implica uma decisão (consciente ou não) diante, por um lado, de tudo aquilo que representa certa tradição, e, por outro, do contexto em que publicará a obra e do impacto que terá sobre ele. A escolha de determinados textos, ao

35 Além das limitações de ordem linguística, a proteção aos direitos autorais e as exigências editoriais são os mais efetivos fatores de controle ao fluxo de textos e ideias. Para uma problematização desse ponto, cf. Derrida (1987, pp. 228-232) e Barreto (2002, pp. 57-65). 
invés de outros, é de responsabilidade do tradutor e inevitavelmente faz parte da sua autonomia no processo de criação de um novo texto.

Toda tradução opera a leitura de um texto específico. Esse ponto, que já foi tratado anteriormente, é óbvio o bastante para que nos limitemos aqui a uma breve reiteração. Todo tradutor elege um texto específico para sua leitura/escritura. Ele é o ponto de partida (ainda que já diferido) da empreitada que terá início por meio de um imprevisível processo de disposição dos significantes textuais numa nova rede de relações com outros significantes. Ou seja, a partir do momento em que começa a leitura desse primeiro texto, uma infinidade de outras leituras (de outros textos) pode vir a entrepor-se ao longo da empreitada: afinal, toda leitura é um processo em larga medida aberto de tentativa de construção de sentido - infinito e sempre à espera do outro que lhe dará um novo princípio. $\mathrm{O}$ tradutor, contudo, no momento em que começa seu trabalho, restringe-se à leitura (já diferida) de um texto específico cujos aspectos "mais importantes" - subjetivamente eleitos por ele - serão empregados como seus pontos de referência.

Toda tradução opera a escritura de um novo texto. Essa tese, que agora deve soar clara o bastante para que possamos chamá-la até mesmo apodítica, foi tradicionalmente rechaçada pela teoria da tradução. Pretendemos ter demonstrado que todo tradutor, mesmo quando inconsciente disto, escreve um novo texto - sendo, portanto, a priori autônomo. Isso é uma mera constatação de fato, não uma proposição que almeje operar aquilo que constata. A tradução só se completa na medida em que um novo texto se apresenta como a conclusão (sempre a diferir-se) da imprevisível construção intentada. Independentemente daquilo que o tradutor pode vir a afirmar sobre seus propósitos - quer ele se empenhe na fidelidade à intenção do autor (ou a um alegado sentido do “original”), quer ele tente reproduzir seus efeitos de linguagem -, ele é a priori autônomo com relação à escolha dos aspectos que em sua leitura serão privilegiados na operação da escritura.

Toda tradução opera a retórica de sua própria existência enquanto tradução. Um tradutor faz suas escolhas acerca dos aspectos "mais importantes" (considerados subjetivamente), tanto nos momentos em que lê quanto nos momentos em que escreve. Essas escolhas, contudo, devem ser justificadas o mais persuasivamente possível (com argumentos de ordem acadêmica, literária, técnica, religiosa, ou de quaisquer outras ordens julgadas necessárias) a fim de convencer outros leitores de que 
sua tradução é como se fosse o "original" - ou antes, de que é como se os aspectos "mais importantes" estivessem nos dois textos. ${ }^{36}$ Ora, cabe ao tradutor compreender suas próprias opções e tentar persuadir o leitor da justeza que o guiou. Uma tradução será considerada tão mais "bemsucedida" (do ponto de vista da recepção, que é - em última instância - determinante de seu status) quanto mais convincentes, relativamente ao que se executar, forem seus argumentos (dentre os quais, ainda hoje, os argumentos de autoridade têm enorme peso). Apesar disso, jamais existirá uma verdade sobre o texto "original". Embora os argumentos se voltem com frequência para ele, a partir do momento em que o tradutor estabelece com os leitores a disputa retórica na qual são escolhidos e defendidos seus aspectos pretensamente "mais significativos" (ou seus elementos "inefáveis" e suas "verdades"), não há nada no texto "original" que deva ser levado em conta a priori de maneira necessária ou objetiva.

Seríamos tentados a elencar ainda um último aspecto que, no entanto, parece estar de certa maneira compreendido no ponto anterior, justamente na medida em que faz parte dos argumentos retóricos que orbitam o texto traduzido. E seria isto: toda tradução traz a assinatura de uma contra-assinatura. Afinal de contas, quem assina o novo texto? O autor do "original" ou o autor da tradução? A questão colocada dessa forma parece não deixar margem a dúvidas, mas toda a tradição escrita de que temos notícia acredita que a tradução deva ser assinada pelo autor do texto "original" (o exemplo mais claro disso sendo a forma como as referências bibliográficas ainda são organizadas - fato que colocamos em questão no presente texto). Ou seja, tradicionalmente se considera que o autor da tradução não é o autor do texto que escreve (paroxismo dos paradoxos!). Se o tradutor faz uma leitura do texto "original" e, nessa medida, coloca-se como a contra-assinatura que todo texto exige para que se cumpra enquanto texto, ${ }^{37}$ por outro lado, sua contra-assinatura termina por se fazer ela mesma a assinatura desse novo texto. A tradução é uma leitura que se faz escritura, ou ainda, uma escritura que opera uma leitura (mesmo que dali outras leituras devam, por sua vez, ter origem). É

36 Concordamos com Meschonnic (1999, p. 21) e, valendo-nos da tradução de Ferreira e Fenerich (2010, p. XXVI), comprovamos que: "Em nenhum caso, mesmo quando é excelente, uma tradução não pode passar, fazer-se passar pelo original. Ela tem sua própria historicidade”. A dupla negação em português aqui é a maior prova disso.

37 Cf. Derrida (1987, pp. 148-156). Com ele parece concordar também Skinner (1996, pp. 113-119), de quem citamos a seguinte frase: "Segue-se que toda assinatura só é uma assinatura se reclamar ou prometer uma contra-assinatura”. Cf. também a nota 9 do presente artigo. 
evidente que - no processo de tradução - leitura e escritura fazem parte de um mesmo movimento: elas complementam-se e, ainda que se insiram numa complicada disputa retórica envolvendo o texto "original", só podem completar-se por meio do novo texto. Não faz sentido, portanto, que o autor do "original" seja considerado também o autor da tradução. Afinal, todo tradutor é o verdadeiro autor do texto que escreve.

\section{V}

Chegandoaoápice da construção aqui empreendida por meio do recurso a certos pilares fundamentais, talvez seja interessante esboçarmos alguns traços dos múltiplos horizontes que se abrem a partir de tal ponto. Tendo partido de reconsiderações sobre o modo de significação tradicional - ou seja, do caráter infinitamente remissivo de toda leitura/escritura -, propusemos uma análise do traduzir, não mais entendido como mera transposição dos signos de um texto "original" num texto conformado a ele, mas revelado na autonomia daquele que o constrói..$^{8}$ Apontamos algumas das possíveis referências que todo tradutor pode levar em conta quando realiza sua empreitada, buscando sempre justificá-las o mais persuasivamente possível a fim de convencer o leitor acerca da precisão de seu projeto.

Toda tradução é um novo texto. A partir dessa constatação, facilmente vislumbramos a consequência de que toda tradução é potencialmente o "original" de uma nova tradução. Essa consequência - apesar de mero desdobramento lógico de nossa tese principal - foi encarada de maneira um tanto quanto dúbia pela tradição. É certo que Benjamin (1921, p. XVII) afirma a impossibilidade de que traduções sejam traduzidas. Essa compreensão parece se dever ao fato de que o sentido se adere de forma excessivamente fugaz nas traduções - o que não se daria no caso de “originais”. Acompanhemos aqui nas palavras de Lages (2013, p. 118):

38 Haroldo de Campos depreende, com razão, do ensaio de Valéry para sua tradução das Bucólicas, que o resultado final de uma tradução seria "transformação mais que conformação". É interessante notar, nesse sentido, a mudança vocabular adotada pelo próprio Haroldo (no mesmo artigo, publicado em 1983), no qual promove uma revisão de pontos de vista anteriormente adotados. Ele afirma: "Em meu ensaio de 1962, 'Da tradução como criação e como crítica', procurei definir a tradução criativa ('recriação', 'transcriação') como uma prática isomórfica (no sentido da cristalografia, envolvendo a dialética do diferente e do mesmo), uma prática voltada para a iconicidade do signo. De uns anos para cá, tenho preferido usar o termo paramorfismo para descrever a mesma operação, acentuando no vocábulo (do sufixo grego para-, 'ao lado de', como em paródia, 'canto paralelo') o aspecto diferencial, dialógico, do processo [...]” (CAMPOS, 2013e, p. 37). 
Quanto mais elevada for a qualidade de uma obra, tanto mais ela permanecerá - mesmo no contato mais fugidio com o seu sentido - ainda traduzível. Isso vale, é claro, apenas para os originais. Traduções, ao contrário, revelam-se intraduzíveis - não por seu peso, mas devido à excessiva fugacidade com que o sentido a elas adere.

Tal entendimento, contudo, encontrou ampla resistência em algumas reflexões realizadas ao longo do século XX. ${ }^{39}$ Haroldo de Campos, por exemplo, afirma que a teoria da tradução benjaminiana - embora radical e subversiva - estaria presa a uma "clausura metafísica" (segundo a expressão de Derrida). Ele afirma ainda que: "Essa 'clausura' é demarcada pela separação categorial, 'ontológica', entre 'original' e 'tradução' que preside persistentemente a essa teoria, não obstante o muito que ela fez para desconstituir o dogma da fidelidade ao significado da teoria tradicional do traduzir [...]" (CAMPOS, 2013b, p. 52). Foi esse dualismo benjaminiano (o qual já havíamos destacado anteriormente $)^{40}$ que lhe impediu de tirar as consequências mais radicais esboçadas por sua teoria.

No esteio de uma revisão daquilo que era compreendido como uma espécie de passividade inerente à tradução, muitos autores consideraram a possibilidade de que textos já traduzidos fossem submetidos a um novo processo de tradução, ou seja, vislumbraram em certa prática do traduzir a novidade original da tradução..$^{41} \mathrm{O}$ próprio Haroldo de Campos cita o vertiginoso processo de um "rubai" (quarteto) transcriado por Augusto de Campos. Esse poeta, a partir da tradução inglesa de Edward Fitzgerald do poema de Omar Kháyyám, transcriou (sem conhecer a língua persa em que o "original" fora escrito) o poema, "guiando-se pela 'forma semiótica', pelo 'intracódigo' do quarteto em inglês, como regulador das opções

39 Cf. Derrida (1987, p. 225). Nas palavras de Barreto (2002, p. 57): "Não existe tradução da tradução, eis o axioma sem o qual não existiria 'A tarefa do tradutor'. Se aí se tocasse, tocar-se-ia, e não se deve fazê-lo, o intocável do intocável, quer dizer, o que garante ao original que ele permaneça de fato o original". Cf. ainda a exegese de Bennington (1991, p. 158) com relação a esse ponto.

40 Cf. nota 25 do presente artigo.

41 Cf. Bennington (1991, p. 158). Nas palavras de Skinner (1996, p. 121): "Determinada tradução ou leitura se deixará retraduzir: Derrida próprio cita as traduções de Sófocles por Hölderlin que são retraduzidas por sua vez, tornando-se com isso originais [...]. Pode-se dizer também, generalizando um pouco o sentido da palavra 'tradução', que todos os textos do próprio Derrida (não) são (mais do que) leituras ou traduções de 'originais', mas se afirmará a originalidade dessas leituras reconhecendo que elas exigem, por sua vez, serem traduzidas [...]". O entendimento segundo o qual determinados textos são traduções de outros textos, além de ter sido previamente apontado por nós, pode ser ainda estendido ao movimento da própria desconstrução derridiana (cf. ARAÚJO, 2008, p. 260). 
reconfiguradoras do texto em português [...]" (CAMPOS, 2013e, p. 40).42 Esse entendimento, com o qual estamos de acordo, parece fortalecer-se cada vez mais entre os estudiosos contemporâneos da tradução. ${ }^{43}$

Esses breves exemplos, ainda que pontuais, atestam que nossas considerações sobre a autonomia do tradutor, a originalidade da tradução e as implicações mais radicais de tais entendimentos estão em consonância com o que outros teóricos têm vislumbrado. Ao que tudo indica, a antiga postura de melancólica passividade do tradutor diante tanto do texto "original" - absolutamente intocável para ele -, quanto de sua própria tradução - inevitavelmente mutilada a seus olhos -, esteja sendo desmascarada. É certo que essa atitude faz parte dos argumentos retóricos disponíveis a todo tradutor para justificar seu texto enquanto tradução. Mas uma vez que se revele a subjetividade inerente a toda escolha daquilo que será levado em conta no momento de se traduzir, já não há mais motivo para a melancolia diante dos aspectos deixados de lado e "irremediavelmente perdidos" na tradução. Já não se pode mais considerar a tradução como secundária com relação ao "original". ${ }^{4}$ Toda

42 Embora Meschonnic (1999, p. 6o) cite a tradução de Fitzgerald como uma obra que permanece clássica, ele nega que traduções possam ser traduzidas. Nas palavras de Ferreira e Fenerich (2010, p. 35): "Esta separação entre língua e texto, sentido e estilo permite a prática frequente, em poetas contemporâneos, de traduzir de uma língua que não se conhece, e que alguns pretendem que seja melhor mesmo não conhecer, ou através de um informante. Isto é ainda tradução? Ou uma imitação do traduzir, do símile-traduzir? É preciso muita indiferença pelo significante para admitir este relaxamento. Malgrado a aparência, pois que os poetas se abandonam a ela, é aos meus olhos uma antipoética". Cf. Meschonnic (1999, p. 116). Apenas o apego ao privilégio conferido à noção de "original" dificulta que esses autores compreendam a originalidade existente em toda obra de tradução.

43 Nesse sentido, até mesmo Lages (2007, p. 205, n. 106), ainda que apenas numa nota a seu estudo sobre Benjamin, afirma: "Uma demonstração divertida (quando desprovida de má-fé editorial e inspirada apenas pelo prazer do jogo literário) - ainda que vertiginosa ou, se quisermos, diabólica - do modo de operação desse falso na tradução é dada pelos experimentos que se lançam a retraduzir traduções. O que ocorre quando traduzimos uma tradução? O antigo original torna-se irrelevante e a tradução se torna ela mesma o original da retradução, e assim por diante, numa cadeia infinita de produção textual de infinitos 'originais'”.

44 É o que defende Derrida (1987, p. 218) quando afirma: "Je voulais plutôt marquer que tout traducteur est en position de parler de la traduction, à une place qui n'est rien moins que seconde ou secondaire. Car si la structure de l'original est marquée par l'exigence d'être traduit, c'est qu'en faisant la loi l'original commence par s'endetter aussi à l'égard du traducteur". Barreto (2002, p. 40) parece apresentar uma interpretação positiva dos termos "seconde ou secondaire" [segundo ou secundário] já que, em tradução ao mesmo trecho, escreve: "Eu gostaria preferencialmente de marcar que todo tradutor está em posição de falar da tradução, em um lugar que não é nada menos que segundo ou secundário. Pois se a estrutura do original é marcada pela exigência de ser traduzido, é que, fazendo disso a lei, o original começa por endividar-se também em relação ao tradutor". 
tradução é o registro de uma construção na qual, para além do acaso que lhe é próprio, inscreve-se uma série de escolhas e decisões pessoais ou seja, uma tradução não implica necessariamente uma entrega, uma renúncia ou uma imposição, não se tratando em suma de uma Aufgabe. ${ }^{45}$

Chegados ao fim desta construção textual, voltamos nossos olhos ao início. Se as considerações de Benjamin nos seguiram ao longo de todo o trajeto, como um eco sempre presente (ainda que vindo de longe), seria de se espantar se não terminássemos ainda em meio a seu cortejo. Gostaríamos aqui de rememorar a bela imagem dos cacos de um vaso seríamos tentados a dizer: ânfora ${ }^{46}$ - como metáfora da tradução (metáfora da tradução que a própria Lages executa do texto de Benjamin): Da mesma forma como os cacos de um vaso, para serem recompostos, devem
encaixar-se uns aos outros nos mínimos detalhes, mas sem serem iguais, a
tradução deve, ao invés de procurar assemelhar-se ao sentido do original,
conformar-se amorosamente, e nos mínimos detalhes, em sua própria língua,
ao modo de visar do original, fazendo com que ambos sejam reconhecidos
como fragmentos de uma língua maior, como cacos são fragmentos de um vaso.
(LAGES, 2013, p. 115)

Essa bela imagem, em que uma perda irremediável se faz inscrita (ainda que mitigada pela promessa de salvação), ${ }^{48}$ remete-nos às palavras pronunciadas pelo professor Jacyntho Lins Brandão (2013) durante uma comunicação realizada na Universidade Federal de Minas Gerais - UFMG. Comentando sua tradução do texto de Luciano, Philopseudés (Os amigos da mentira), cujo público-alvo era juvenil, ele dizia ter ficado em dúvida com relação à "melhor" tradução para a palavra grega amphoreús. Se, por um lado, a opção mais óbvia parecia ser "ânfora” (palavra derivada do mesmo vocábulo grego, mas assaz rebuscada para seus "jovens leitores"), e, por outro, o editor lhe sugeria um simples "vaso", o tradutor acabou decidindo, face às contingências, vertê-lo por um corriqueiro "balde" (BRANDÃO, 2014, p. 59). Ora, talvez esse corajoso gesto metaforize a situação que pretendemos ter vislumbrado - ou cujo vislumbre acreditamos ter apontado - na forma como o tradutor pode encarar seu

45 Para maiores detalhes sobre a palavra escolhida por Benjamin para figurar no título de seu texto "Die Aufgabe des Übersetzers", cf. a nota assinada por Gagnebin (enquanto editora), contida em: Lages (2013, p. 101, n. 40).

46 Segundo a opção da tradução contida em: Barck et al. (2008, p. 61).

47 Cf. Benjamin (1921, pp. XIV-XV).

48 Para uma das interpretações possíveis dessa passagem (em cotejo a outros escritos de Benjamin), cf. Gagnebin (2009, pp. 19-30). 
texto: não mais como o caco de um vaso quebrado, mas como um balde - mundano em sua exposição às imprevisíveis circunstâncias do destino, ainda que resistente o bastante para continuar inteiro após uma pretensa queda. ${ }^{49}$

\section{VI}

Completemos nossa argumentação com uma proposta de tradução para uma poesia de Walter Benjamin, "Der Schwan”. Trata-se do texto que o autor propõe como tradução ao poema "Le cygne", de Charles Baudelaire, e que é parte integrante da seleção dos Tableaux parisiens [Quadros parisienses], publicados por Benjamin em 1923.50 Abdicando completamente do "original" francês, pretendemos demonstrar que um dos axiomas fundamentais da teoria da tradução de Benjamin não se sustenta: seu poema é dotado de uma originalidade digna da assinatura de seu autor alemão e reclama, por isso, uma tradução que seja sua contra-assinatura e que o assine, por sua vez, também em português.

Valemo-nos aqui da autonomia de todo tradutor, a fim de propor um texto que busca reproduzir - tanto quanto possível aos limites de nosso engenho - a forma do poema de Benjamin: em decassílabos, o mais das vezes heroicos (embora, às vezes, se recorra também a decassílabos sáficos, como o próprio Benjamin faz), com rimas alternadas, nosso poema pretende reapresentar a estranheza de um autor alemão da República de Weimar que escreve sobre a Paris de meados do séc. XIX e recorre, para isso, a imagens tanto clássicas quanto contemporâneas. A sintaxe e o léxico do alemão também se fazem sentir em nossos versos, ameaçando qualquer pretensa aspiração a algo próximo de uma "transparência" ou de um emprego "naturalizado" da língua portuguesa. As construções e imagens barrocas do poema de Benjamin foram retomadas sempre que possível, embora sua parcimônia simbolista no emprego da pontuação nem sempre tenha sido retomada em nosso poema. O resultado deve ser julgado pelo leitor, mas gostaríamos que pelo menos parte do sabor dos

49 O texto de Brandão (2014) foi considerado uma "tradução e adaptação", embora o próprio autor (ao fim da supracitada comunicação) tenha levantado dúvidas com relação a tal etiqueta. Até que ponto também não adapta um tradutor, cujo público-alvo é adulto? Ou ainda, será que o texto traduzido por quem afirma não ter nenhum público-alvo (enquanto realiza sua tradução) não é em nada adaptado?

50 Para mais detalhes sobre o processo tradutório empreendido por Benjamin (1923), em seu Charles Baudelaire, Tableaux parisiens, cf. Raulet (2014). 
versos do autor de Das Passagen-Werk pudesse ser encontrado também neste novo poema de um brasileiro do séc. XXI, escrevendo em meio a um período de grave crise política e social em seu país e em todo o mundo.

\section{O cisne}

Dedicado a Victor Hugo

I

Eu penso em ti, Andrômaca! $\mathrm{O}$ arroio Que, escuro e raso espelho, antigamente

Te acolheu e a teu grande desapoio, Simóis, que agora flui a quem lamente,

De repente em meus sensos penetrou, Na via para o novo Carrossel.

Se a novidade (a antiga urbe passou!)

Nos muda, as vilas vão fundo a granel.

Vejo todo lugar entre barracas, Torsos, pilastras - sem que eu veja a cena -

Onde entre blocos e musgosas cloacas

Nas vitrines o caos venal acena.

Havia aí um parque de animais, Onde um dia, ao rocio, quando esgares

Da faina erguiam-se e um tropel de pás

Cedia o breu de um furacão aos ares,

Em frente da gaiola um cisne achei, a Lançar seus membranosos pés no solo

E sua branca asa através da areia.

O seco arroio ao sequioso fez de tolo

E ele arrastava ao pó, plumosa, a luva,

Dizendo à imagem de seu lago idílico:

“Quando hás de vir, ó água? Quando, ó chuva?"

Eu vi o desvalido - evento mítico -

Contra o céu, amiúde, como Ovídio, Contra o céu, cujo azul inflama em seus

Cruores, a cabeça erguer... Dissídio

Iniciando e clamando contra Deus.

II

Paris é outra, mas perdura igual

Melancolia. A nova urbe antiga

Se torna um alegórico areal

E as memórias me pesam como vigas. 
Die Autonomie des Übersetzers - Desconstruindo os ... - 848

Em frente ao Louvre, aqui, me pesa um cofre:

Penso em meu cisne - em como se evadia

Tão ridiculamente quanto sofre

Um exilado - e também em ti: a

Andrômaca tirada do consorte;

que foi dada ao prazer de Pirro, o obsceno;

que se deitou num túmulo sem morte;

e era de Heitor e iria para Heleno.

Penso na negra que se exaure em lágrimas,

Agoniza na lama e - olhar lameiro -

Sente saudades das palmeiras da África,

Perante as quais se adensa um nevoeiro.

Penso também naqueles que um anseio

Adoece e de lamúrias se enriquecem

("Miséria", a loba, lhes concede o peito):

Nos órfãos cujas florações fenecem.

Pelo meu bosque, a voz desses sem-voz

Escuto ecoar mementos tão fortuitos

Penso em marujos esquecidos sós

Prisioneiros vencidos... Outros muitos.

\section{Der Schwan $^{51}$}

Victor Hugo gewidmet

I

Ich denke dein, Andromache! Der Bach

Der trübe seichte Spiegel welcher einst

Dich aufnahm und dein hohes Ungemach

Simois, der nur strömte wenn du weinst

Ist plötzlich in mein Sinnen eingedrungen

Beim Gange übers Neue Caroussel.

Die Altstadt ist dahin - wenn Neuerungen

Uns wandeln sinken Städte doppelt schnell.

Ich sehe jenen Platz mit den Baracken

Den Torsi und Pilastern noch im Geist

Wo zwischen Blöcken und bemoosten Schlacken

Ein feiler Trödel in den Fenstern gleisst.

51 Para o texto alemão, cf. Benjamin (1923, pp. 9-13). 
Dort war ein Tierpark aufgebaut gewesen Wo einst im frühen Froste wenn im Freien Die Tagfron aufsteht und ein Heer von Besen Die Schwärze des Orkans der Luft verleihen

Vor seinem Käfig einen Schwan ich fand Der seinen Schwimmfuß übers Pflaster zog Und seinen weißen Fittich durch den Sand; Als dann der trockne Bach den Durstigen trog

Wälzt er im Staub sein zuckendes Gefieder Und sprach erfüllt vom Bild der Heimatseen „Wann wirst du fallen, Naß? Wann, Blitz, fährst du hernieder?“

Ich sah den Armen - mythisches Geschehn -

Gen Himmel oft wie bei Ovidius der Verbannte

Gen Himmel dessen Bläue grausam loht

Den Kopf so recken daß sein Hals sich spannte Als sende seinen Vorwurf er zu Gott.

II

Paris wird anders, aber die bleibt gleich Melancholie. Die neue Stadt die alte Mir wirds ein allegorischer Bereich Und mein Erinnern wuchtet wie Basalte.

Selbst hier vorm Louvre liegt es schwer auf mir Ich denk an meinen Schwan, wie er entwich

So lächerlich so groß wie dieses Tier Verzehren sich Verbannte - und an dich

Andromache die dem Gemahl entglitten Die unter Pyrrhus feil ward zum Genuß Die überm leeren Sarkophag gelitten Und Hektors war und ward des Helenus.

Ich denk der Schwarzen die von Sucht verzehrt Im Schlamm sich quält und mit verstörten Blicken Die Zauberpalmen Afrikas entbehrt Vor denen zähe Nebel sich verdicken;

Und aller derer welche ein Verlust Unheilbar kränkte, all der Tränenreichen (Die Wölfin ,Jammer' nahm sie an die Brust) Der Waisen deren Blumenhäupter bleichen.

Durch meinen Wald die Ruh des Ruhelosen Hör ich wie Hornruf ein Erinnern wandern Ich denk im Riff vergessener Matrosen 
Die Autonomie des Übersetzers - Desconstruindo os ... - 850

Gefangener Besiegter... vieler andern.

\title{
DIE AUTONOMIE DES ÜBERSETZERS - DECONSTRUCTING THE METAPHYSICAL ASSUMPTIONS OF TRADITIONAL TRANSLATION STUDIES
}

\begin{abstract}
Taking some fundamental points of the post-structuralist linguistic theory as pillars of our argument (from Jacques Derrida, Geoffrey Bennington and their translators to Portuguese), the present paper searches to question some "truths" traditionally accepted in the theory and practice of translation (even in radical authors, as Walter Benjamin and Henri Meschonnic, for instance). Criticizing certain notions of "originality", "literality", "fidelity" and others related to what Derrida would call a "metaphysics of the presence", we undertake to demonstrate convincingly the autonomy that is a prerogative of every translator, even when he explicitly refuses it. It is not therefore an attempt to claim more autonomy to translating, but to verify a de facto situation: every translator is the author of the text he conceives. In this sense, every text - whether it be an "original", whether it be a translation - is endowed with an originality that authorizes it to be translated subsequently (and in an indefinite way). This conclusion contradicts one of the main axioms of the text "Die Aufgabe des Übersetzers" (traditionally translated as "The task of the translator" and that serves as a preface to Benjamin's translations to Charles Baudelaire's “Tableaux parisiens" [Parisian Scenes]), i.e., that one translation cannot be further translated. Our argument culminates justly in a translation of the poem "Der Schwan", from Benjamin, proposed as a translation of the poem "Le cygne", from Baudelaire: suggesting that every translator is the author of the text of his translation and enters thereat in a game of signatures and counter-signatures, we think we demonstrate the originality of Benjamin's poem when we offer a Portuguese version of it, opening up a brand new field of investigations to translation theory and practice.
\end{abstract}

Keywords: Walter Benjamin; Jacques Derrida; Translation Theory.

\section{$\overline{\text { REFERÊNCIAS }}$}

ARAÚJO, Nabil. De uma certa “consciência traduzante”... Tradução/Desconstrução - Entre Benjamin e Derrida. Revista de Letras, v. 49, n. 2, 2009, pp. 243-263. Disponível em: <http://seer.fclar.unesp.br/letras/article/view/2051/1679>. Acesso em: 9 jan. 2018.

BARCK, Karlheinz et al. A tarefa do tradutor. Por Walter Benjamin. In: BRANCO, Lúcia Castello (org.). A tarefa do tradutor, de Walter Benjamin: quatro traduções para o português. Belo Horizonte: Fale/UFMG, 2008, pp. 51-65. Disponível em: <http:// www.letras.ufmg.br/vivavoz/data1/arquivos/atarefadotradutor-site.pdf $>$. Acesso em: 9 set. 2017 .

BARRETO, Júnia. Torres de Babel. Por Jacques Derrida. Belo Horizonte: Editora UFMG, 2002. 
Remate de Males, Campinas-SP, v.38 n.2, pp. 827-852, jul./dez. 2018 - 851

BENJAMIN, Walter. Tableaux parisiens - Charles Baudelaire: Deutsche Übertragung mit einem Vorwort über die Aufgabe des Übersetzers von Walter Benjamin. Heidelberg: Verlag von Richard Weissbach, 1923.

BENNINGTON, Geoffrey. Derridabase. In: DERRIDA, Jacques; BENNINGTON, Geoffrey. Jacques Derrida. Paris: Éditions du Seuil, 1991, pp. 7-292.

BORGES, Jorge Luis. La biblioteca de Babel. In: Ficciones. Madrid: Alianza Editorial Madrid, 1971a, pp. 89-100.

BORGES, Jorge Luis. Pierre Menard, autor del Quijote. In: Ficciones. Madrid: Alianza Editorial Madrid, 1971b, pp. 47-6o.

BORGES, Jorge Luis. Las versiones homéricas. In: Obras completas I. Madrid/Barcelona: Emecé, 1996, pp. 239-243.

BRANDÃO, Jacyntho Lins. As belas infiéis: Luciano no salão de Monsieur d'Ablancourt. Palestra proferida durante a XII Semana de Pós-graduação em Estudos Clássicos e Medievais: "Reelaborações dos Clássicos", na FALE/UFMG (Belo Horizonte), em 19 de novembro de 2013.

BRANDÃO, Jacyntho Lins. Os amigos da mentira. Por Luciano de Samósata. Texto traduzido e adaptado; ilustrações Luis Matuto. 1. ed. Belo Horizonte: Fino Traço, 2014 .

CAMPOS, Haroldo. Da tradução como criação e como crítica. In: Transcriação. Org. Marcelo Tápia, Thelma Médici Nóbrega. 1. ed. São Paulo: Perspectiva, 2013a, pp. 1-18.

CAMPOS, Haroldo. Para além do princípio da saudade. In: Transcriação. Org. Marcelo Tápia, Thelma Médici Nóbrega. 1. ed. São Paulo: Perspectiva, 2013b, pp. 47-59.

CAMPOS, Haroldo. Paul Valéry e a poética da tradução. In: Transcriação. Org. Marcelo Tápia, Thelma Médici Nóbrega. 1. ed. São Paulo: Perspectiva, 2013c, pp. 61-76.

CAMPOS, Haroldo. Texto literário e tradução. In: Transcriação. Org. Marcelo Tápia, Thelma Médici Nóbrega. 1. ed. São Paulo: Perspectiva, 2013d, pp. 19-26.

CAMPOS, Haroldo. Tradução, ideologia e história. In: Transcriação. Org. Marcelo Tápia, Thelma Médici Nóbrega. 1. ed. São Paulo: Perspectiva, 2013e, pp. 37-45.

DERRIDA, Jacques. Des tours de Babel. In: Psychés: Inventions de l'autre. Paris: Éditions Galilée, 1987, pp. 203-235.

DERRIDA, Jacques. Du droit à la philosophie. Paris: Éditions Galilée, 1990.

DERRIDA, Jacques. La voix et le phénomène: Introduction au problème du signe dans la phénoménologie de Husserl. 2. ed. Paris: Presses Universitaires de France, 1972. 
Die Autonomie des Übersetzers - Desconstruindo os ... - 852

FERREIRA, Jerusa Pires; FENERICH, Suely. Poética do traduzir. Por Henri Meschonnic. São Paulo: Perspectiva, 2010.

GAGNEBIN, Jeanne Marie. História e narração em Walter Benjamin. São Paulo: Perspectiva, 2009 .

HORKHEIMER, Max; ADORNO, Theodor. Dialektik der Aufklärung: Philosophische Fragmente. 21. Auflage. Frakfurt am Main: Fischer Taschenbuch Verlag, 2013.

LAGES, Susana Kampff. Walter Benjamin: tradução e melancolia. 1. ed. São Paulo: Editora da Universidade de São Paulo, 2007.

LAGES, Susana Kampff. A tarefa do tradutor. Por Walter Benjamin. In: GAGNEBIN, Jeanne Marie (org.). Escritos sobre mito e linguagem (1915-1921). Por Walter Benjamin. Trad. de Susana Kampff Lages e Ernani Chaves. 2. ed. São Paulo: Duas Cidades/Editora 34, 2013, pp. 101-119.

LORD, Albert. The Singer of Tales. New York: Atheneum, 1971.

MAGALHÃES, Lucy. A voz e o fenômeno: introdução ao problema do signo na Fenomenologia de Husserl. Por Jacques Derrida. Rio de Janeiro: Jorge Zahar, 1994.

MESCHONNIC, Henri. Poétique du traduire. Paris: Éditions Verdier, 1999.

PARRY, Milman. The Making of Homeric Verse: The Collected Papers of Milman Parry. Ed. Adam Parry. Oxford: Claredon Press, 1971.

RAULET, Gérard. L'atelier du traducteur. Benjamin et les Tableaux parisiens. Revue italienne d'Études Françaises, v. 4, 2014, pp. 2-8.

SKINNER, Anamaria. Derridabase. Por Geoffrey Bennington. In: SKINNER, Anamaria. Jacques Derrida. Por Geoffrey Bennington e Jacques Derrida. Rev. Márcio Gonçalves, Caio Mario Ribeiro de Meira. Rio de Janeiro: Jorge Zahar Ed., 1996, pp. 11-217.

WEIL, Simone. L'Iliade ou le poème de la force. In: L'Iliade ou le poème de la force: et autres essais sur la guerre. Paris: Éditions Payot \& Rivages, 2014, pp. 71-116. 